\title{
Analysis on Stability of Three-dimensional High Cutting Slope based on Finite Element Strength Reduction Method
}

\author{
Liming Wu ${ }^{1, a}$, Zijian Wang ${ }^{2,3, b,{ }^{*}}$,Rong Gao ${ }^{3, c}$, Sichang Wang ${ }^{3, d}$, Jinpeng $\mathrm{Hu}^{3, \mathrm{~b}}$ \\ ${ }^{1}$ Chongqing Technology and Business Institute, Chongqing, China, 400052 \\ ${ }^{2}$ National Engineering Research Center for Inland Waterway Regulation,
}

Chongqing Jiaotong University, Chongqing ,China,400074;

${ }^{3}$ Chongqing University of Science \& Technology, Chongqing, China, 401331

a58432053@qq.com, b121687678@qq.com, ${ }^{\text {c550229643@qq.com, }{ }^{\mathrm{d}} 123508599 @ q q . c o m, ~}$

\begin{abstract}
Keywords: High slope .Stability analysis.Strength reduction finite element method(FEM).
Abstract. Stability of high cutting slope concerns safety pass of road at the bottom of slope and has relationship with security and stability of buildings on the top of slope. On the basis of ANSYS finite element strength reduction method, this paper does elastoplastic nonlinear and large deformation geometric nonlinear analysis on slope. In terms of three-dimensional deformation of space, this paper utilizes Drucker -Prager elastoplastic model in finite element analysis and uses full N-R in large deformation analysis. Analyses on three-dimensional homogeneous high cutting slope show that three-dimensional slope model established through finite element strength reduction method could visually simulate the process of slope becoming unstable with increasing of reduction coefficient, in which better safety coefficient of slope could also be acquired. The utilization of strength reduction method in analyzing slope stability not only overcomes assumed slide of limit equilibrium method but also intuitively acquires sliding tendency and practical plastic sliding area of slope, which provides effective way for stability analysis on high cutting slope after excavation.
\end{abstract}

\section{Introduction}

With the rapid development of our transportation infrastructure and quickening pace of road construction, the following traffic construction needs a lot of slopes being excavating. Being limited by location along road, a large part of slope excavation should be high cutting. Safety and stability during high cutting excavation of road are common technical problems in geotechnical engineering [1]. Therefore for the purpose of avoiding it, analysis on stability should be done ahead. At present there exist two methods [2,3] for analyzing slope stability. The one is traditional rigid limit equilibrium method which is based on Mohr-Coulomb Shear Strength Theory. It divides landslide into several vertical slices, in which equilibrium equation is established to solve safety coefficient through force acted on vertical slices. Under the circumstance of assumption that internal force transmission among neighbor rock and soil masses differs, this method includes Swedish Circle Method, Simplified Bishop Method, Simplified Ordinary Slice Method, Morgenstern-Price Method and Unbalanced Thrust Transmission Method. Limit equilibrium method does not take stress-strain relationship of soil mass into consideration, which could not truly reflect stress field and displacement field of slope destabilization. Another one utilizes numerical analysis method which considers stress-strain relationship of soil mass thus overcoming disadvantage of limit equilibrium method. Numerical analysis method mainly includes finite element method, adaptive finite element method, discrete element method, Lagrange element method and interface element method. Finite element method considers deformation characteristics of medium, which truly reflects stress states of slope, could be suitable for various boundary conditions and irregular geometry and keeps high applicability. Therefore this paper takes one typical high cutting slope of road as engineering background, does analysis on stability of three-dimensional slope through utilizing finite element strength reduction method and does comparison on the analysis results and other methods thus coming to the conclusion 
that finite element strength reduction method keeps effectiveness and applicability on stability analysis of slope, which provides preferences for stability analysis on high cutting slope.

\section{Finite Element Strength Reduction Method}

Rationale of Strength Reduction Method.The section headings are in boldface capital and lowercase letters. Second level headings are typed as part of the succeeding paragraph (like the subsection heading of this paragraph).

Strength reduction method means ratio between the maximum shear strength provided by soil mass inside the slope and practical shear stress produced by external load in the slope under the condition of external load being unchanged. The following formulas shows shear strength parameters after reduction $[4,5]$.

$$
\begin{aligned}
c_{m} & =c / F_{r} \\
\varphi_{m} & =\arctan \left(\tan \varphi / F_{r}\right)
\end{aligned}
$$

In the formulas above, $c$ and $\varphi$ stand for cohesion and internal friction angle provided by original rock and soil. $c_{m}$ and $\varphi_{m}$ stand for cohesion and internal friction angle needed for keeping balance after reduction.

Steps of Finite Element Strength Reduction Method Analyzing Slope Stability.Set of pre-processing module includes element selection, material property definition, model establishment and mesh generation. Set of solution module includes boundary constraints of model, load application of model and solution setup.Post-processing module displays calculation results in the shape of diagram and table.Reselect material parameters which are mainly and after reduction and do solution until calculation being not convergence namely plastic zone penetration appears. Then stability of slope could be comprehensively determined according to displacement, strain and plastic zone.

\section{Engineering Project Analysis of Finite Element Strength Reduction Method}

\section{Description of Engineering Project.}

This paper chooses one typical high cutting slope of road as example. This slope considers elastoplasticity. Fig.1 and Tab.1 shows slope model size and its initial physical parameters.

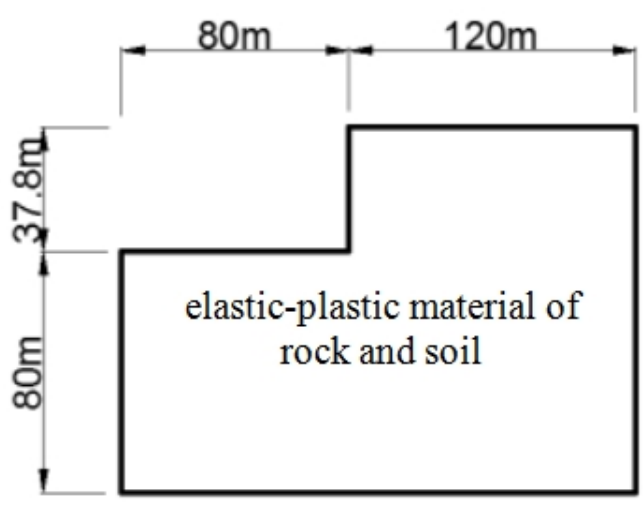

Fig.1 Slope Model Diagram

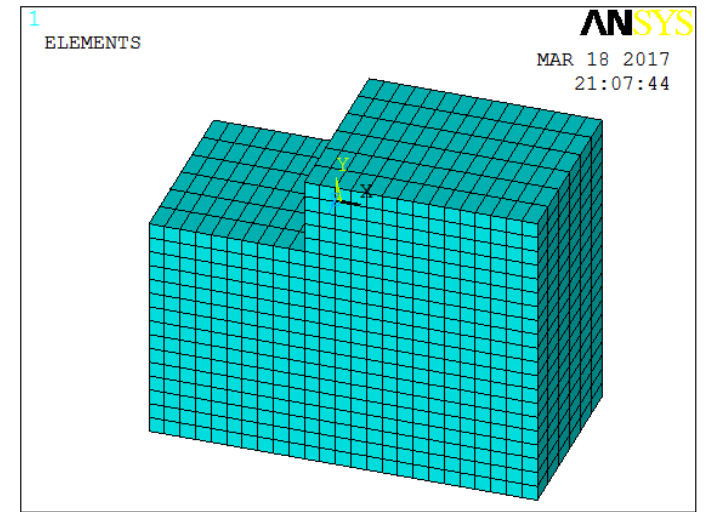

Fig.2 Rock-soil Mass Parameters of Slope Model

Tab.1 Rock-soil Mass Parameters of Slope Model

\begin{tabular}{|c|c|c|c|c|c|}
\hline Category & $\begin{array}{c}\text { Elastic } \\
\text { modulus }\end{array}$ & $\begin{array}{c}\text { Poisson } \\
\text { ratio }\end{array}$ & Multiplicity & Cohesion & $\begin{array}{c}\text { friction } \\
\text { angle }\end{array}$ \\
\hline $\begin{array}{c}\text { geotechnic } \\
\text { al slope }\end{array}$ & $28 \mathrm{GPa}$ & 0.24 & 25 & $0.24 \mathrm{MPa}$ & $20^{0}$ \\
\hline
\end{tabular}


During model analysis, strength reduction coefficient $\mathrm{F}$ is divided into five parts including 1.0, 1.2, 1.4, 1.6 and 1.7. Tab.2 shows the corresponding physical parameters' reduction conditions.

Tab.2 Working Condition Table of Physical Parameter Reduction of Rock and Soil Mass

\begin{tabular}{|c|c|c|}
\hline Reduction factor & Cohesion $(\mathrm{KPa})$ & internal friction angle(0) \\
\hline 1.0 & 240 & 20 \\
\hline 1.2 & 200 & 16.67 \\
\hline 1.4 & 171 & 14.29 \\
\hline 1.6 & 150 & 11.76 \\
\hline 1.7 & 141 & 11.11 \\
\hline
\end{tabular}

Finite Element Stability Analysis.This paper utilizes finite element software ANSYS to do slope strength reduction simulation analysis. It also uses Drucker -Prager ideal elastoplastic model and large deformation full Newton -Raphson namely full N-R to do solution. The established finite element model of high cutting slope is shown in Fig.2. Through doing analysis on reduction coefficients of different working conditions in tab.2, we acquire plastic strain contours of slope model from Fig. 3 to Fig.7.

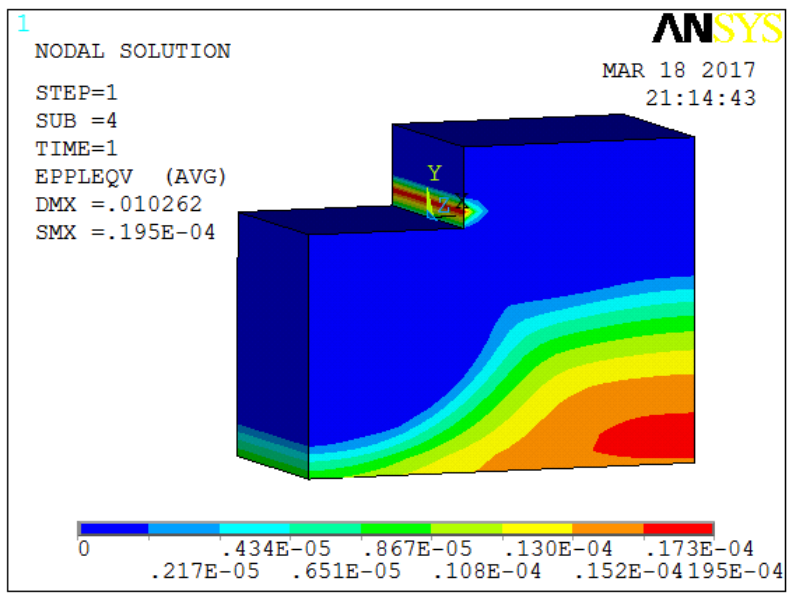

Fig.3 Plastic Strain Contour of Slope Model under Reduction Coefficient $F$ being 1

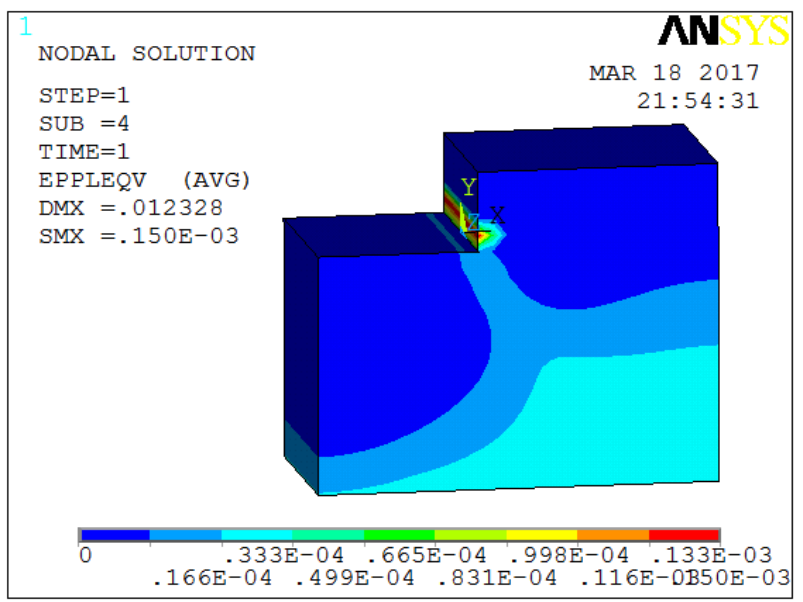

Fig.5 Plastic Strain Contour of Slope Model under Reduction Coefficient $\mathrm{F}$ being 1.4

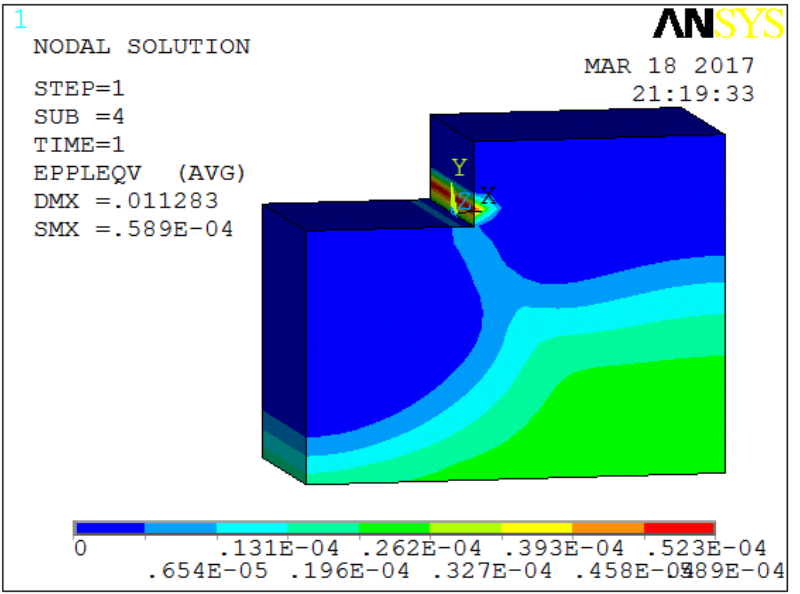

Fig.4 Plastic Strain Contour of Slope Model under Reduction Coefficient $\mathrm{F}$ being 1.2

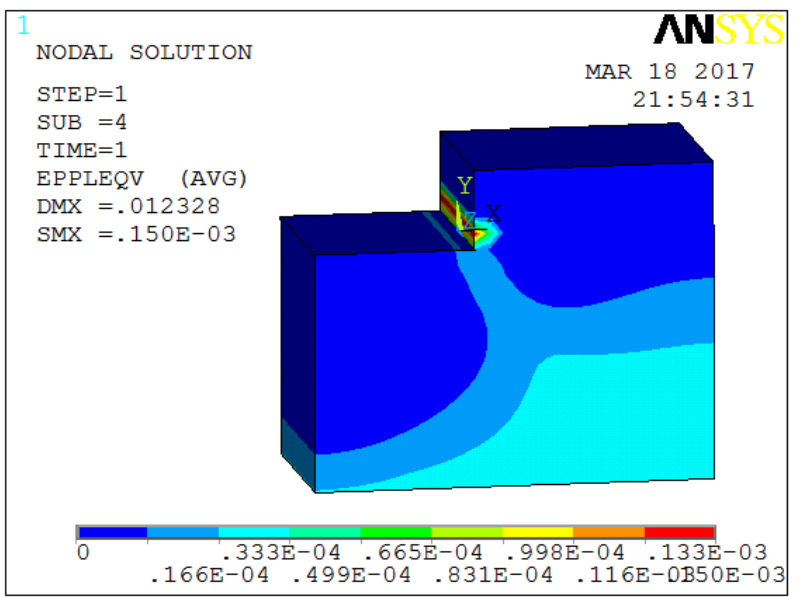

Fig.6 Plastic Strain Contour of Slope Model under Reduction Coefficient $\mathrm{F}$ being 1.6 


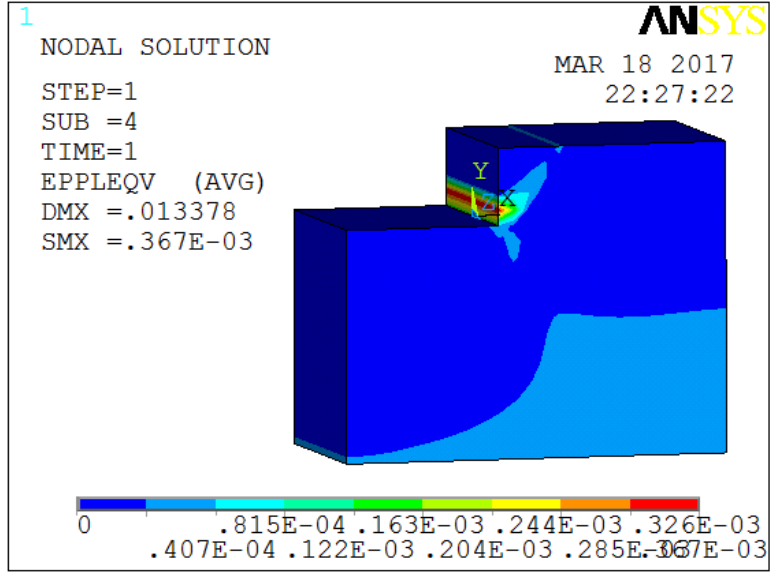

Fig.7 Plastic Strain Contour of Slope Model under Reduction Coefficient $F$ being 1.65

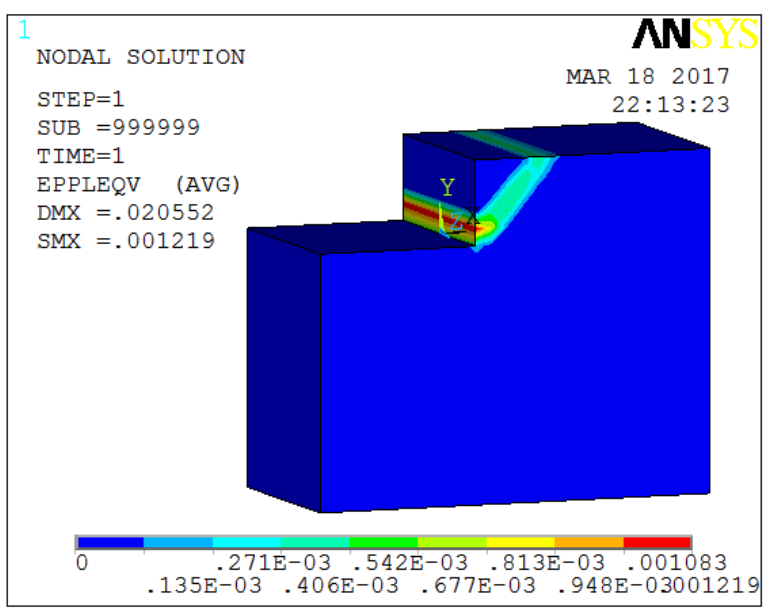

Fig.9 Plastic Strain Contour of Slope Model under Reduction Coefficient $F$ being 1.75

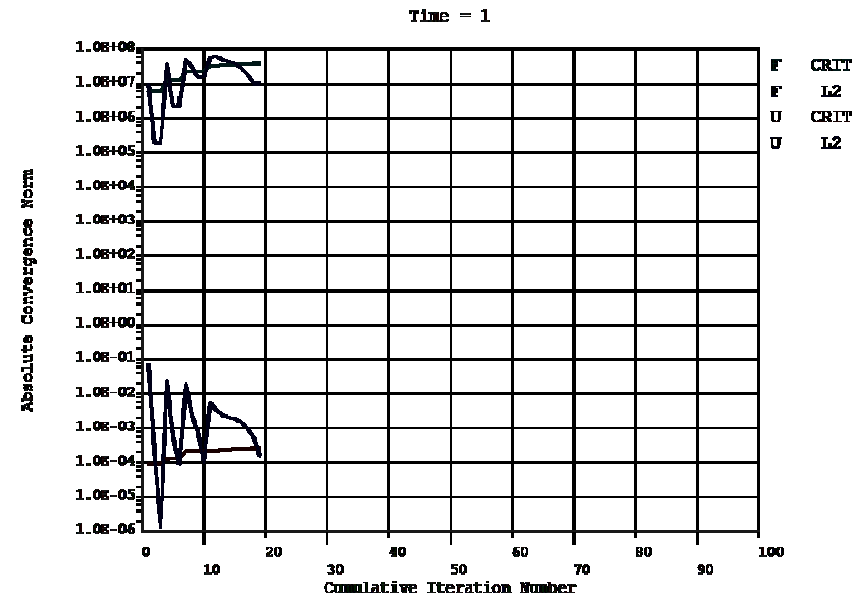

Fig.8 Iteration Solution Process Chart under Reduction Coefficient $F$ being 1.65

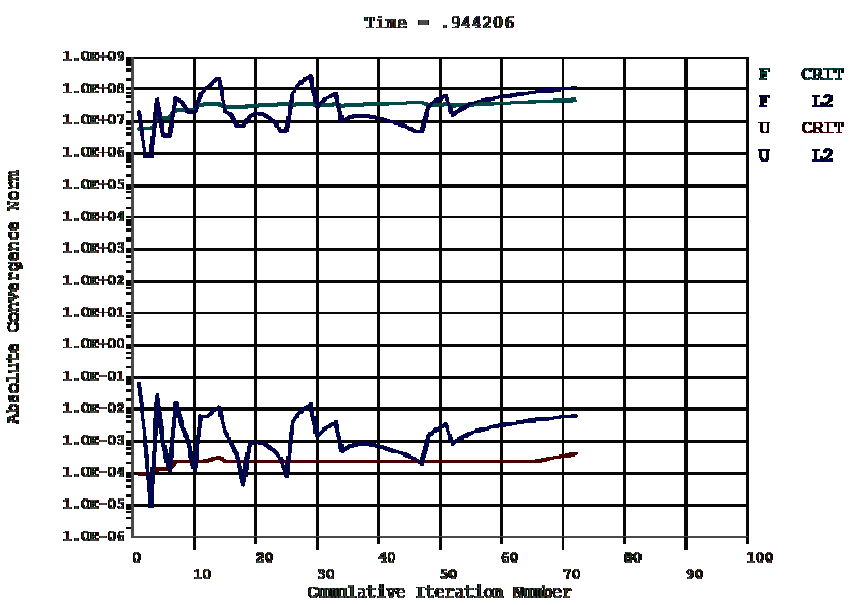

Fig.10 Iteration Solution Process Chart under Reduction Coefficient $F$ being 1.75

Fig. 3 to Fig.10 show that plastic zone of slope gradually increases with the increasing of reduction strength. When $\mathrm{F}$ becomes 1.75, plastic zone becomes penetrating from slope foot to top during which iteration solution process curve is not convergent. This shows that slope has failed to be stable. It could be estimated that stability coefficient of this slope is 1.7. According to slope regulation, it stays in stable state at present.

Comparison on Slope Stability Analyses of Different Calculation Methods.Do comparison between safety coefficients of three-dimensional slope stability analyzed through finite element strength reduction method and those of traditional two-dimensional slope stability analyzed by methods including Swedish Slice Method, Simplified Bishop Method and Janbu Method. Tab.3 shows the compared safety coefficients.

Tab.3 Safety Coefficients Acquired through Different Stability Calculation Methods

\begin{tabular}{|c|c|c|c|c|}
\hline Analyzing & $\begin{array}{c}\text { Strength } \\
\text { Reduction } \\
\text { method }\end{array}$ & $\begin{array}{c}\text { Swedish Slice } \\
\text { Method }\end{array}$ & $\begin{array}{c}\text { Simplified Bishop } \\
\text { Method }\end{array}$ & $\begin{array}{c}\text { Janbu } \\
\text { Method }\end{array}$ \\
\hline $\begin{array}{c}\text { Safety coefficient } \\
\text { of stability }\end{array}$ & 1.70 & 1.811 & 1.739 & 2.003 \\
\hline
\end{tabular}

Safety coefficient comparison in Tab.3 shows that strength reduction method acquires the minimum safety coefficient while Janbu Method acquires the maximum one. Safety coefficient of strength reduction method is similar to that of Simplified Bishop Method whose difference is $2.3 \%$. Difference value between strength reduction method and Swedish Slice Method is 6.5\%. These show that 
analyzing result of strength reduction method is similar to that of limit equilibrium method. Strength reduction method keeps high security.

\section{Conclusions and Suggestions}

This paper does simulation analysis on safety coefficients of one typical high cutting slope of road after excavation through utilizing finite element strength reduction method. It also does comparison on safety coefficients of various analyzing methods and acquires the following conclusions.

1) Three-dimensional slope model established through utilizing finite element strength reduction method could visually simulate instability process of slope with the increasing of reduction coefficient and better acquire safety coefficient size of slope.

2) Utilization of strength reduction method on analyzing slope stability would effectively overcome assumption sliding of limit equilibrium method and could visually acquire slope sliding tendency and practical plastic sliding area.

3) Compared with other traditional limit equilibrium methods, finite element strength reduction method acquires lower safety coefficient. From the angle of engineering safety, it could be utilized in engineering practice.

4) On the basis of finite element strength reduction method, this paper does calculation and analysis on high cutting slope stability of road. Although it could reflect slope instability process well, this method does not take influencing factors of soil layer, rock and soil saturation, excavation disturbance and earthquake into consideration. Therefore essential indoor and outdoor experiments are still needed for the purpose of acquiring more accurate safety coefficients of slope stability.

\section{Acknowledgements}

This work was financially supported by the University-level key project of Chongqing Technology \&Business Institute(Grant:ZD2015-01);Key Laboratory of Hydraulic and Waterway Engineering of the Ministry of Education, Chongqing Jiaotong University(Grant:SLK2015B02);Science and technology research project of Chongqing Education Commission(Grant:KJ1601339,KJ1501336, KJ1501332);Project supported by the Natural Science Foundation of Chongqing(Grant:cstc2017jcyj AX0189,cstc2016jcyjA0463);Postdoctoral special projects funded by Chongqing Government(Xm2 014108);Production safety in Chongqing cityscience and technology project(Grant:CQAWS2013Y006); Funded by Research Foundation of Chongqing University of Science\&Technology, the project No.is(Grant:CK2016B09);Science and technology research project the School of Civil Engineering and Architecture(Grant:201711).

\section{References}

[1]Lin Xiaosong,Xu Jiang Chen Hongkai. eal.Evaluation of high-cutting along highway in mountainous area .Journal of Wuhan University of Technology(Transportation Science \& Engineering),Vol.718-722(2011),p.35.

[2] Wang Xiaodong,Chen Shoulong.Subgrad finite element analysis slope stability[J]. Anhui Architecture,2011, (1):134, 114.

[3]Renxi Hu, Shiting Kang.Finite element analysis in civil engineering from entry to the master.China machine press(2013).

[4]Jiang Zhaohua, LiJixiang, DUANWen-fu.Analysisof Slope Stability by Strength Reduction Finite Element Method Journal of Wuhan Polytechnic University,Vol.73-76(2008),p.27.

[5]Kang Fei,Jianwei Zhang.ABAGUS application in geotechnical engineering.China Water \& Power Press(2009). 